\title{
Research on the Prediction of the State-of-health of Starting Batteries of Diesel Engines
}

\author{
Tung-Chou Lin ${ }^{*}$ and Liang-Ruei Chen \\ National Changhua University of Education, No. 2, Shi-Da Road, Changhua 500, Taiwan
}

(Received Nevember 12, 2017; accepted December 19, 2017)

Keywords: state-of-health, AC impedance, sensing system, linear regression

A study of state-of-health (SOH) prediction for diesel engine generator starting batteries is presented, the main purpose of which is to analyze the battery's state using the relationship between AC impedance and voltage. A sensing system capable of detecting battery open-circuit voltage and discharge current has been designed. The respective AC impedances at 100 and $50 \%$ battery $\mathrm{SOH}$ were obtained from a monitoring system, and linear regression was used to predict battery SOH. A new GS GTX7A-12B lead acid battery was used in the experiments and the results showed that there was a $11.265 \%$ difference between the actual battery $\mathrm{SOH}$ and that predicted by linear regression.

\section{Introduction}

The development of renewable energy is essential in addressing the issues of global warming and sustainable growth. Renewable energy sources are commonly utilized in microgrids. Hybrid power systems are gaining popularity thanks to the increasing use of renewable energy resources. ${ }^{(1-3)}$ Microgrid systems that rely on diesel generators combined with renewable energy generation systems and the main electrical grid to provide electricity are very common. ${ }^{(4-10)}$ The key technologies required to use a diesel generator in a microgrid are synchronous operation and load sharing. ${ }^{(11-16)}$ Therefore, back-up power is a necessity for heavily powerreliant facilities such as hospitals, office buildings, and hi-tech factories. ${ }^{(17)}$ Currently, all diesel engine generators use lead acid batteries for starting. The battery management system, in addition to the chemical materials, is among the most studied of lead acid battery topics. However, research has been mainly focused on the accurate prediction of remaining battery capacity and balancing control methods. Battery state-of-health ( $\mathrm{SOH}$ ) prediction is a relatively less explored topic. The battery SOH describes the process of actual capacity loss due to use over time. The battery $\mathrm{SOH}$ is closely related to its residual and maximum capacity and has a direct impact on the functional stability of all kinds of electronic systems. Different types of battery SOH detection devices are comercially available. The working principle of a battery life tester is that the aging status of a battery is judged from the voltage drop created when the tested battery discharges high current to a high power load. Battery life testers of this type

*Corresponding author: e-mail: 1tc8488@gmail.com

http://dx.doi.org/10.18494/SAM.2018.1825 
are inconvenient to carry and are often integrated with battery chargers. A $12 \mathrm{~V}$ battery tester determines the aging status of a battery by analyzing its voltage, cold cranking current, and resistance. Measurement of the battery internal resistance is corrected by the cold cranking current measurement. Measurements must be carried out when the battery is fully charged. The battery life detection unit judges the change in output capacity by the difference in voltage with and without loading. The battery aging status is determined by an examination of the voltage decay/change and aging curve. However, further improvements in accuracy and practicality need to be made to these testing methods. The lead acid battery SOH prediction method proposed in this paper establishes the battery AC impedance model by analyzing the AC impedance obtained by the detection system. An experiment has been designed to identify the model parameters and also to obtain the relationship between the internal properties of the battery and the $\mathrm{SOH}$. Linear regression was then used to compare the AC impedance of different batteries and predict battery $\mathrm{SOH}$.

In this study, a brand new lead acid battery was used to predict the $\mathrm{SOH}$ of other batteries. A detection sensor system was designed that is capable of detecting open-circuit voltage and discharge current. The battery $\mathrm{SOH}$ and associated $\mathrm{AC}$ impedance were obtained by the monitoring system and linear regression was then used to predict the $\mathrm{AC}$ impedance for different SOH. Finally, a GSGTX7A-12B lead acid battery was submitted to thorough testing. The results indicate an average difference of $11.265 \%$ between the actual AC impedance measured and the predicted value obtained by linear regression.

\section{System Analysis}

\subsection{Diesel engine generator}

A diesel engine generator is a synchronous machine that converts mechanical energy into electrical energy (AC). Lead acid batteries are often used to start diesel engine generators by the application of a DC current to the rotor coils. The $\mathrm{SOH}$ of the lead acid batteries is therefore very important for starting the diesel engine. The DC current needed to start and maintain the operation of a diesel engine generator is provided by an external battery, and high-torque is needed to crank the diesel engine fast enough to cause compression and ignition of the fuel. The DC generator driven by the engine not only controls the fuel and electricity used by the diesel engine but also charges the battery. The capacity of the battery must be sufficient to withstand more than three times the large current discharge to the starting motor. This makes prediction of the starting battery SOH very important.

\subsection{AC impedance analysis of batteries}

In the $\mathrm{SOH}$ prediction method described here, the battery $\mathrm{SOH}$ is determined by $\mathrm{AC}$ impedance analysis, which reveals the charge and discharge capacity of a battery. ${ }^{(8)}$ Figure 1 shows a complete AC impedance model of a lead acid battery. The electrode inductances $L_{d 1}$ and $L_{d 2}$ are created by the anode and cathode. Ohmic resistance $R_{O}$ represents the resistance created by the electrode metal, electrolyte, and terminal. The terms $R_{c t 1}$ and $R_{c t 2}$ are charge 


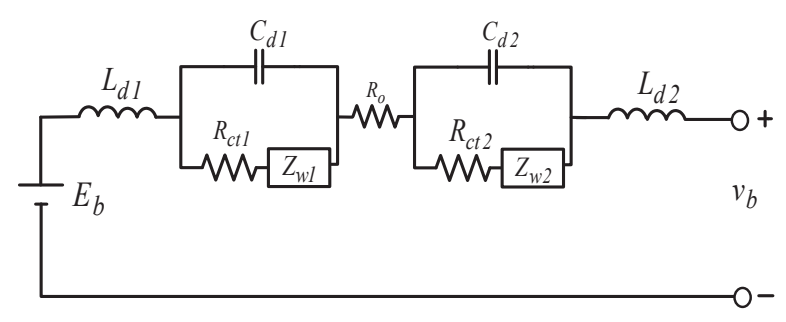

Fig. 1. The complete AC impedance model of a battery.

transfer resistances, which determine the speed of charge transfer on the electrode surface; in other words, the ease with which the electrode reacts and activates energy. Double-layer capacitances $C_{d 1}$ and $C_{d 2}$ result from the capacitor-like structure formed on the electrode surface when it is in contact with electrolyte solution and the ions of opposite charge are attracted to each other. Double-layer capacitance occurs at the interface of the electrode surface and the electrolyte solution and is affected by temperature, ion concentration, and the coarse electrode surface. The Warburg impedance $Z_{w}$ represents the impedance resulting from ion diffusion caused by reactants and products that are approaching and moving away from electrode surfaces in a chemical reaction. Lastly, the AC impedance created is connected to a voltage source $E_{b}$. Figure 2 shows the simplified AC impedance model of a battery. This equivalent series-parallel circuit includes an electron transfer resistor, ion diffusion resistor, double layer capacitor, an ohmic resistor, and an electrode inductor $L_{d}$ finally connected to an ideal battery voltage source $E_{b} .{ }^{(9-11)}$ Since the Warburg impedance $Z_{w}$ has influence only on the AC impedance at low frequency and the battery charge is above $1 \mathrm{~Hz}$, the ion diffusion resistance can be ignored. ${ }^{(12-14)}$ The high-frequency AC impedance model of a battery is shown in Fig. 3. The AC impedance analysis of batteries is a technique widely used in electrochemistry studies.

\subsection{Lead acid battery and SOH}

Lead acid batteries have the following advantages. Easy maintenance: The gas generated inside the battery during charging is absorbed by the electrode plates and reduced to an electrolyte solution. The electrolyte solution level does not drop significantly. Highly immobilized solution: The electrolyte solution is absorbed by the glass-fiber separators and is well contained. Superior safety: The excessive gas produced by inappropriate charging operations is automatically discharged through safety valves and battery cracking is prevented. Low self-discharge: The use of special lead-calcium alloy plates reduces self-discharge to a minimum. Long battery life and high economic effect: Electrode plates made of anti-corrosion lead-calcium alloy have a longer float charging life. Long battery life is achieved by the use of special separators to contain the electrolyte solution and keep the active material in contact with the anode plates so that the material does not fall from the plates. Longer cycle life is also achieved by deep discharge, making the batteries highly reliable and economical. Low internal resistance: Low internal resistance facilitates high current discharge and thus better discharge efficiency is achieved. Excellent deep discharge recovery: Long-term discharges normally 


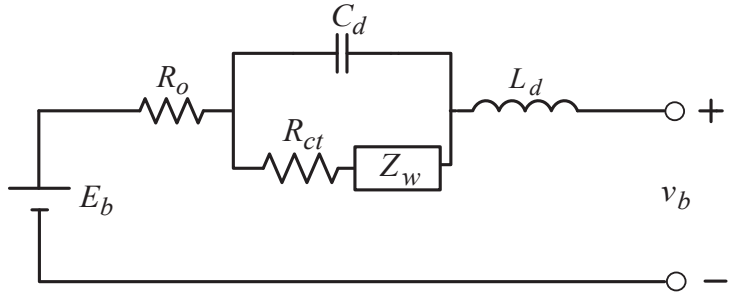

Fig. 2. Simplified AC impedance model of a battery.

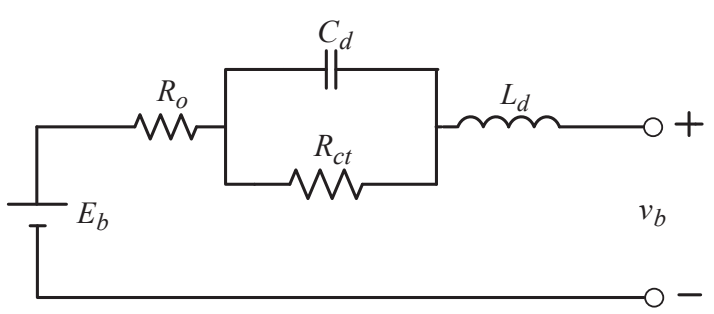

Fig. 3. AC impedance model of a battery at middle and high frequency.

harm load-connected batteries. However, battery capacity is not reduced and performance can be restored quickly if the battery is fully charged.

Batteries convert energy through an electrochemical reaction and the electrical and chemical energy is produced and stored in an oxidation-reduction reaction. However, factors such as environmental change or externally-added energy may cause a loss of reactants or structural changes in the materials during the reactions, resulting in a decay that decreases the amount of energy the battery can provide. These are the main reasons that contribute to the gradual decrease of battery capacity. The performance of a battery system deteriorates even under normal operating conditions. The battery SOH is defined in Eq. (1):

$$
S O H=\frac{Q_{\text {aged }}}{Q_{\text {rate }}} \times 100 \%,
$$

where $Q_{\text {rate }}$ is the rated capacity of a new battery and $Q_{a g e d}$ is the actual capacity after use.

\section{Testing Platform and Experiment Flow}

\subsection{Battery SOH testing platform}

A schematic diagram of the battery SOH testing platform used in this study is shown in Fig. 4. This is used for the monitoring system and sensing system of $\mathrm{SOH}$ prediction for diesel generator starting batteries. The battery $\mathrm{SOH}$ testing platform is composed of detection and monitoring systems, a battery SOH prediction device, battery SOH display, and the lead acid battery. The system includes open-circuit voltage detection and discharge current detection. A Hall element is used to detect the instantaneous values of voltage and current. The monitoring system uses an Huasu H3G-TA and a power recorder.

\subsection{Experimenal process and testing $\mathrm{SOH}$}

Aging inevitably leads to a drop in the rated capacity of a battery. A battery with less than $50 \%$ of rated capacity is no longer suitable for use in a kinetic application. In other words, at 


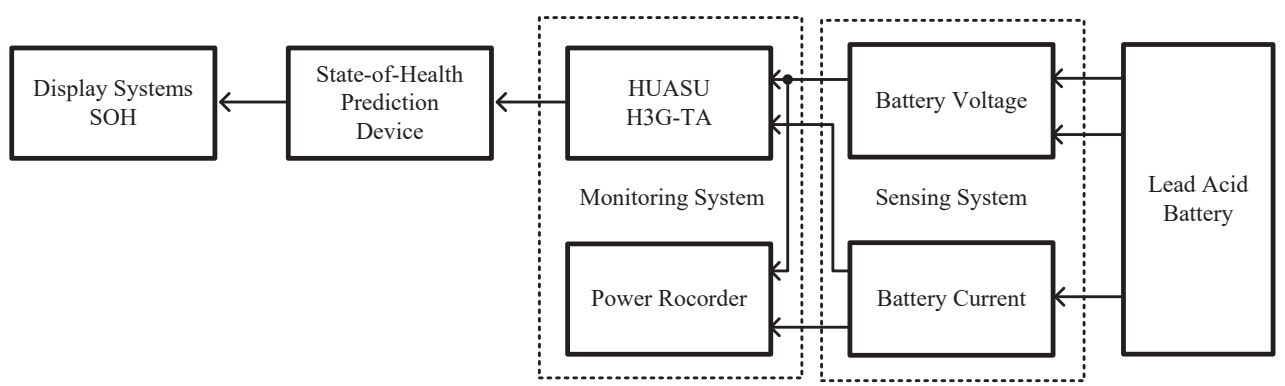

Fig. 4. Battery SOH testing platform.

that capacity, the diesel generator starting battery has reached its limit and needs to be replaced. Our $\mathrm{SOH}$ prediction experiment is designed to measure the $\mathrm{AC}$ impedance at an $\mathrm{SOH}$ between 100 and $50 \%$.

Figure 5 is a flow chart that shows the steps taken in the preparation of a database of $Z$ and $\mathrm{SOH}$ between 100 and $50 \%$. To start, a brand new lead acid battery is fully charged. The detection system is then used to measure the open-circuit voltage and discharge current of the battery. The AC impedance is measured using the monitoring system. The battery is discharged at a fixed current of $0.5 \mathrm{~A}$, and Huasu H3G-TA and the power recorder of the monitoring system are used to measure the $\mathrm{AC}$ impedance and voltage at 100 and $50 \%$ of $\mathrm{SOH}$. The database is established using the relational equation for $\mathrm{AC}$ impedance, voltage, and $\mathrm{SOH}$ using linear regression.

Figure 6 shows the experimental flow chart for the prediction of battery SOH. The steps are as follows. First, the lead acid battery is fully charged. The detection sensor system is then used to measure the open-circuit voltage and discharge current of the battery. Its AC impedance is then measured using the monitoring system. The battery is then discharged at a constant current of $0.5 \mathrm{~A}$, and Huasu H3G-TA and a power recorder are used to measure the AC impedance and voltage. The AC impedance is used to predict the battery $\mathrm{SOH}$ by reference to the database of $Z$ and $\mathrm{SOH}$ between 100 and $50 \%$ of SOH.

Figure 7 shows a diagram of the prediction of battery $\mathrm{SOH}$. The AC impedance and voltages of a new lead acid battery are detected at 100 and $50 \%$ of SOH. The relational equation of $Z$ and $\mathrm{SOH}$ is obtained using linear regression techniques and then used to predict battery $\mathrm{SOH}$ within a range of 100 and $50 \%$.

\section{Experimental Methods}

To obtain the most reliable battery charging data, the battery is kept in an isolation box for the duration of the charging experiments. This ensures that the effect of changes in ambient temperature is minimized. Table 1 is a list of the specifications of the experimental equipment.

First, the SOH of a brand new No. A GSGTX7A-12B lead acid battery is measured. The AC impedance, voltage, and capacity are also measured and recorded. A linear regression model of the relationship between the dependent variable (AC impedance) and dependent variables (voltage 


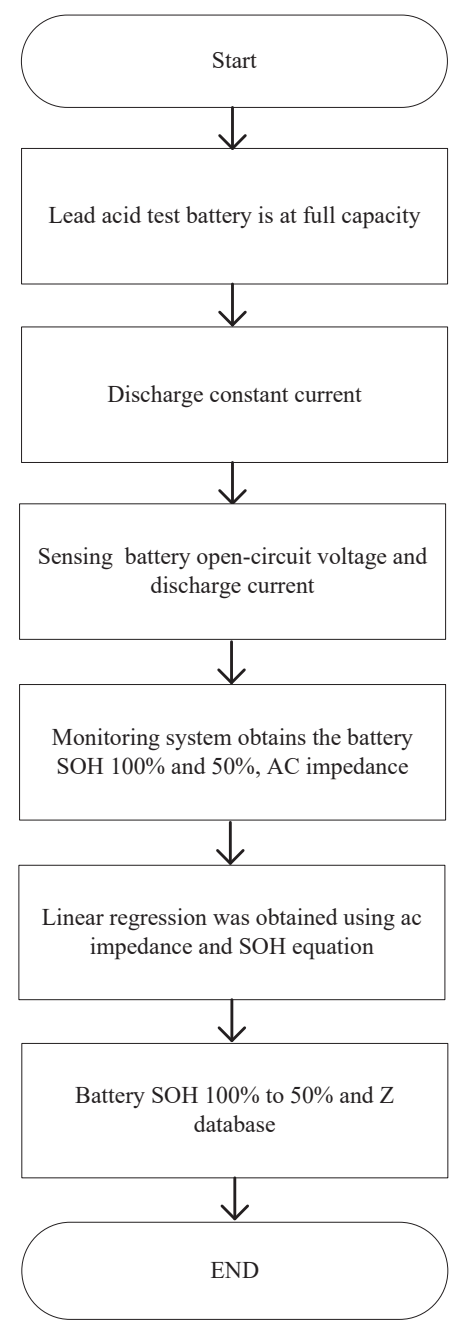

Fig. 5. Establishing a database of $Z$ and $\mathrm{SOH}$ of batteries with SOH between 100 and 50\%.

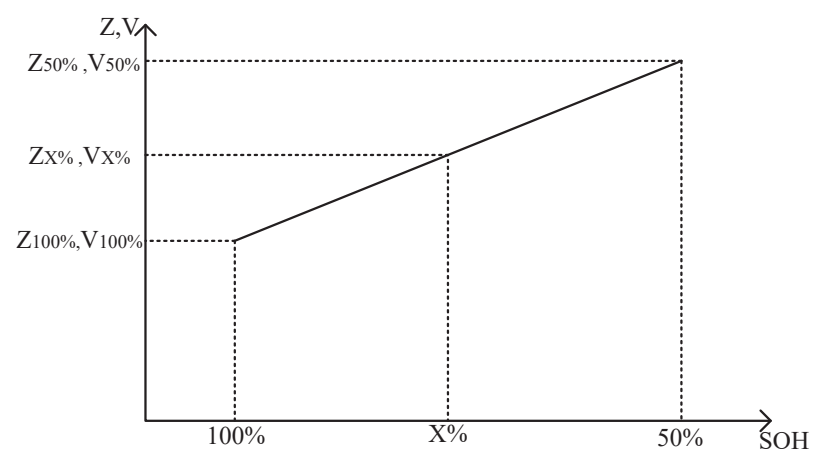

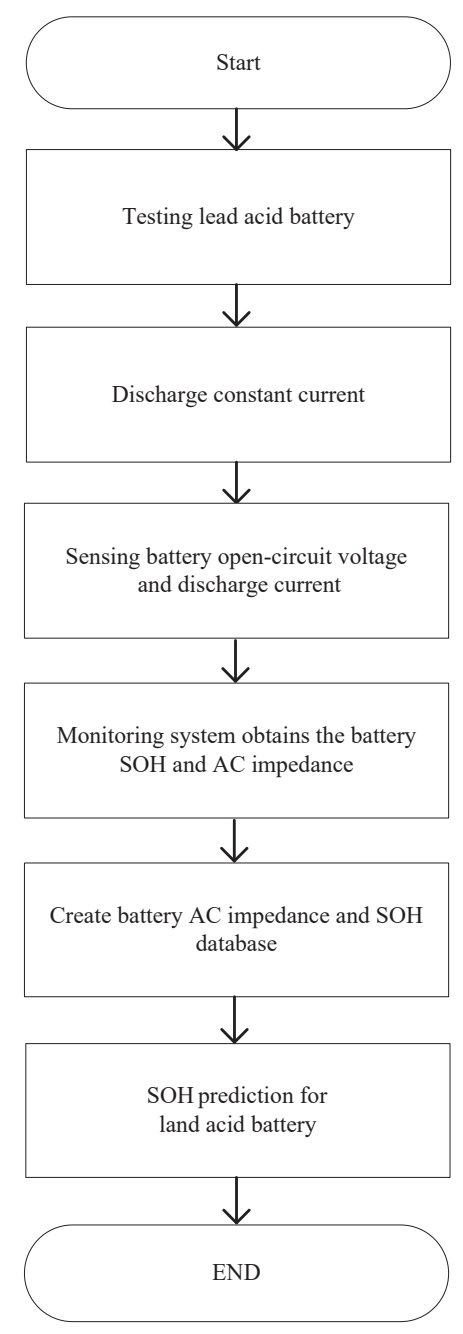

Fig. 6. Flow chart of the battery $\mathrm{SOH}$ prediction experiment .

Table 1

Specifications of the equipment used in the experiments.

\begin{tabular}{lc}
\hline Experiment equipment & Model \\
\hline Battery monitor & Huasu H3G-TA \\
Battery tested & GS GTX7A-12B \\
Power supply & GW GPS-3303 \\
Discharge load & $10 \Omega$ \\
Sensor system & Hall element \\
Power recorder & Hioki \\
\hline
\end{tabular}

Fig. 7. Battery $\mathrm{SOH}$ prediction diagram. 
and capacity) is established. The relational coefficients of the three variables are estimated using regression. The estimated $\mathrm{AC}$ impedance is then obtained by substituting the values of the three relational coefficients into the equation.

The open-circuit voltage and discharge current are measured using the detection system. The battery monitoring system is then used to establish a database of the relationship between $\mathrm{Z}$ and $\mathrm{SOH}$ of the battery between 100 and $50 \%$ of SOH. Table 2 shows the SOH database for battery No. A GSGTX7A-12B between 100 and $50 \%$ of SOH.

It can be seen in Table 3 that the average error of measurement is only $11.265 \%$. A histogram of the $\mathrm{AC}$ impedance curve of actual measurements (battery $\mathrm{A}$ ) and predictions are shown in Fig. 8.

Table 2

SOH database for the brand new lead acid battery No. A GSGTX7A-12B between 100 and 50\% of SOH.

\begin{tabular}{lccc}
\hline Battery capacity (\%) & $\begin{array}{c}\text { Actual measurement } \\
\text { AC impedance }(\mathrm{m} \Omega)\end{array}$ & $\begin{array}{c}\text { AC impedance by linear } \\
\text { estimation }(\mathrm{m} \Omega)\end{array}$ & Error rate (\%) \\
\hline 100 & 37.243 & 37.196 & 0.125 \\
90 & 34.167 & 33.297 & 2.544 \\
80 & 32.917 & 33.495 & 1.727 \\
70 & 32.769 & 33.720 & 2.821 \\
60 & 33.632 & 33.702 & 0.210 \\
50 & 34.514 & 33.828 & 1.985 \\
\hline
\end{tabular}

Table 3

AC impedance error rate: Actual measurement and database value for battery No. A and No. B GSGTX7A-12B.

\begin{tabular}{lccc}
\hline Battery capacity (\%) & $\begin{array}{c}\text { Battery A } \\
\text { AC impedance by linear } \\
\text { estimation }(\mathrm{m} \Omega)\end{array}$ & $\begin{array}{c}\text { Battery B } \\
\text { Actual measurement } \\
\text { AC impedance }(\mathrm{m} \Omega)\end{array}$ & Error rate (\%) \\
\hline 100 & 37.196 & 32.722 & 12.03 \\
90 & 33.297 & 29.791 & 10.53 \\
80 & 33.495 & 28.255 & 15.65 \\
70 & 33.720 & 28.164 & 6.49 \\
60 & 33.702 & 29.338 & 12.95 \\
50 & 33.828 & 30.466 & 9.94 \\
\hline
\end{tabular}

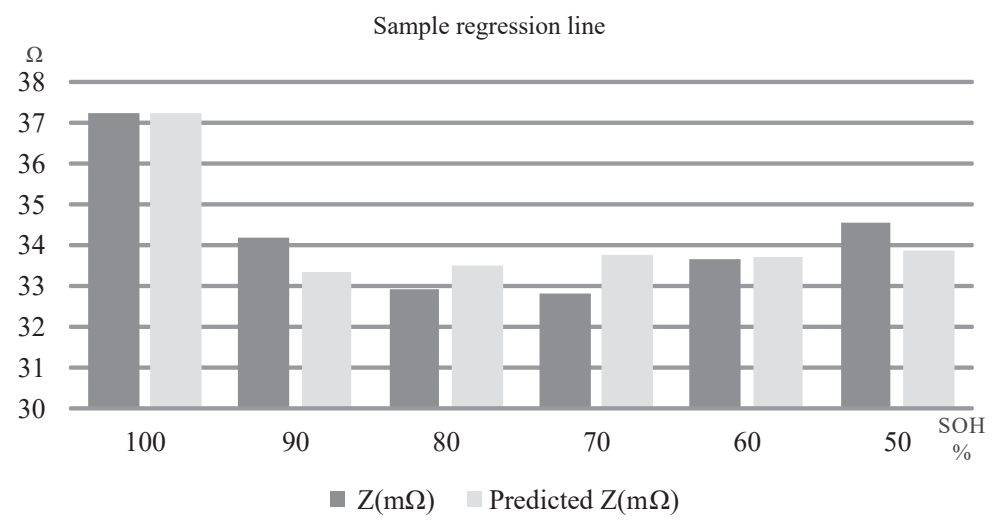

Fig. 8. (Color online) Histogram of measured and predicted AC impedance for battery GSGTX7A-12B. 


\section{Conclusions}

An $\mathrm{SOH}$ prediction method for a diesel generator starting battery is proposed. In these experiments, the $\mathrm{AC}$ impedance and voltages were measured and linear regression technique was used to obtain the relational equation of $Z$ and $\mathrm{SOH}$, which was in turn used to predict battery $\mathrm{SOH}$ in the range of 100 and $50 \%$. The $\mathrm{SOH}$ of the battery under test can be predicted immediately by substituting its $\mathrm{AC}$ impedance into the linear equation governing the relationship between battery $\mathrm{SOH}$ and $\mathrm{AC}$ impedance. The battery $\mathrm{SOH}$ obtained from online measurements has an error rate of $11.265 \%$ compared to the prediction.

\section{References}

1 K. Hu, V. Sivaraman, B. G. Luxan, and A. Rahman: IEEE Sens. J. 16 (2016) 1488.

2 S. Jeong, Y. J. Jang, and D. Kum: IEEE Trans. Power Electron. 30 (2015) 6369.

3 C. J. Govar and J. A. Banner: IEEE Aerosp. Electron. Syst. Mag. 18 (2013) 17.

4 R. Ahmed, M. E. Sayed, I. Arasaratnam, J. Tjong, and S. Habibi: IEEE J. Emerging Sel. Top. Power Electron. 2 (2014) 678

5 A. H. Ranjbar, A. Banaei, A. Khoobroo, and B. Fahimi: IEEE Trans. Smart Grid 3 (2012) 360.

6 M. Coleman, C. K. Lee, C. Zhu, and W. G. Hurley: IEEE Trans. Ind. Electron. 54 (2007) 2550.

7 L. Guo, C. Hu, and G. Li: Ind. Electron. Appl. (ICIEA) (2015) 1458.

8 S. Vazquez, S. M. Lukic, E. Galvan, L. G. Franquelo, and J. M. Carrasco: IEEE Trans. Ind. Electron. 5712 (2010) 3881.

9 C. Pearson, K. Schrantz, and J. Neubaue: Proc. IEEE Aerosp. Conf. (2010) 1.

10 W. Luo, C. Lv, L. Wang, and C. Liu: Proc. IEEE Ind. Electron. Appl. (2011) 1943.

11 J. D. Dogger, B. Roossien, and F. D. J. Nieuwenhout: IEEE Trans. Energy Convers. 26 (2011) 256.

12 R. Li, J. Wu, H. Wang, and G. Li: Proc. IEEE Ind. Electron. Appl. (2010) 684.

13 Yuasa Battery Co., Ltd: NP type battery, http://www.yuasa.com.tw/product-detail.php?nId=29

14 Y. D. Lee, S. Y. Park, S. B. Han, K. Norregaard, L. Overgaard, and F. Elefsen: IEEE Trans. Ind. Appl. 51 (2015) 498.

15 Y. Ma, B. Li, G. Li, J. Zhang, and H. Chen: IEEE/CAA J. Autom. Sin. 4 (2017) 195.

16 L. R. Chen, S. L. Wu, and D. T. Shieh: IEEE Trans. Ind. Electron. 60 (2013) 88.

17 S. L. Wu, H. C. Chen, and S. R. Chou: Energies 11 (2014) 3438.

\section{About the Authors}

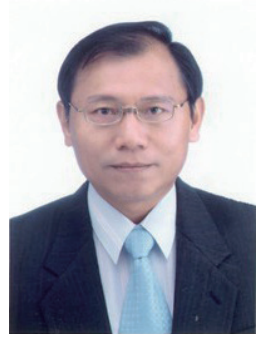

Tung-Chou Lin received a M.S. degree in the Department of Electrical Engineering, National Changhua University of Education, Changhua Taiwan, in 2010. He is currently working toward the Ph.D. degree in the Department of Electrical Engineering, National Changhua University of Education, Changhua. His research interests are battery charger and control applications.

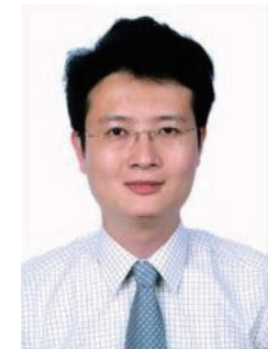

Liang-Rui Chen received B.S., M.S., and Ph.D. degrees in electronic engineering from National Taiwan University of Science and Technology, Taipei, Taiwan, in 1994, 1996, and 2001, respectively. He joined the faculty of the Department of Electrical Engineering, National Changhua University of Education, Changhua, in August 2006, where he is currently Professor. His major research interests are power electronics, battery-powered circuit design, and renewable energy. 